\title{
De Argelia a París: ¿escritores «alienados»? ${ }^{1}$
}

TRISTAN LEPERLIER CNRS - Théorie et histoire des arts et des littératures de la modernité (THALIM) Traducción de Analía Gerbaudo y Santiago Venturini. Universidad Nacional del Litoral - CONICET, Argentina / analia.gerbaudo@conicet.gov.ar / venturini.santiago@gmail.com

Cada vez más se acusa a la literatura de escritores francófonos periféricos publicados en Francia de hacerle el juego al mercado. Ese fue el caso particular de la literatura argelina publicada en Francia durante la guerra civil de los años 90, cuya visibilidad fue notoria. La sospecha comercial fue doble y contradictoria: caía tanto sobre los escritores considerados en Argelia «inauténticos» y «oportunistas» por su búsqueda estratégica de la aprobación extranjera como también, especialmente en Francia, sobre los editores y la recepción franceses, considerados «etnocéntricos» dado que se interesaban solo en ciertos aspectos del texto (como la violencia) adaptándolo incluso para un consumo más fácil del lectorado francés. Esta doble sospecha es la réplica de una doble valorización mucho más extendida, de larga data en el lectorado argelino, respecto de los escritores publicados en el extranjero, y reciente para el lectorado europeo, respecto de las literaturas "poscoloniales». La sospecha, aunque minoritaria, constituye aún hoy un lugar común ya que circula entre los círculos intelectuales de las dos orillas, entre escritores, la prensa y trabajos académicos. Trataremos de introducir otros matices: ¿en qué medida las obras literarias de los escritores argelinos francófonos están orientadas hacia un lectorado francés? ¿En qué medida la recepción y la edición francesas pueden calificarse como «etnocéntricas»? En definitiva, y para retomar un término desprestigiado en el contexto argelino, ¿en qué medida es legítimo considerar que los escritores argelinos de lengua francesa están «alienados», convertidos en extranjeros para sí mismos cuando publican en Francia?

Esta problemática nos invita a fijarnos aquí una doble ambición, a la vez teórica y metodológica. Teórica, en la medida en que se trata de plantear la necesidad de pensar la literatura argelina de lengua francesa y el conjunto de las literaturas francófonas no francesas como el producto de un espacio literario transnacional. ${ }^{2}$ Son escasas las críticas que ponen en relación los polos argelino y extranjero de la literatura argelina: los enfoques sociales de la literatura argelina se concentran en el polo argelino (Miliani) o sobre el polo francés (Harchi); sobre este último, más prestigioso, se concentran la mayoría de las micro-lecturas. Ahora bien, en las entrevistas que realizamos (Leperlier, 2018a), los escritores que publican en Argelia citan espontáneamente a escritores que

Para citar este artículo: Leperlier, T. (2019). De Argelia a París: ¿escritores «alienados»? El taco en la brea, 10 (junio-noviembre), 193-208. Santa Fe, Argentina: UNL. DOI: 10.14409/tb.vii10.8698 
publican en el extranjero incluso para negarles su estatuto de escritores «argelinos»: confirman así que la literatura nacional en la que se inscriben se establece más allá de las fronteras geográficas.

El carácter transnacional del espacio literario argelino se definió durante la época colonial, cuando París era ya el lugar central de publicación de los escritores de Argelia. Este se perpetuó después de la Independencia por razones económicas (Miliani:30) y políticas ${ }^{3}$ (las editoriales nacionales no tenían la capacidad o la voluntad de publicar todos los manuscritos de escritores francófonos) pero también por razones simbólicas: como en todas las literaturas periféricas (Casanova), la publicación en los grandes centros internacionales confiere un prestigio superior. Esta jerarquización implícita del espacio literario explica la violencia de los discursos de quienes no acceden a un reconocimiento equivalente porque no pudieron, por una u otra razón, internacionalizarse.

La ambición metodológica del artículo se concentra en el uso que se hace con frecuencia de las entrevistas a escritores. Conviene, sin duda, tomarlas en serio. Pero no podrían constituir una «verdad» sobre los textos sin el riesgo de empobrecerlos considerablemente (a pesar de la «muerte del autor», esta tendencia crítica persiste); tampoco podrían constituir una verdad sobre el «etnocentrismo» del aparato crítico francés o sobre el «oportunismo» de los participantes: es necesario atender a la circulación de nociones y de discursos entre escritores e investigadores. Resulta conveniente, entonces, historizar estas entrevistas y situarlas en su espacio de enunciación: confrontar las entrevistas entre ellas y con el discurso social (Angenot) que las rodea, y del mismo modo, confrontarlas con el archivo, la estadística y el estudio a la vez paratextual e interno de las obras. Nos basaremos aquí en una investigación que comprende alrededor de 80 entrevistas semiestructuradas, materiales de prensa, archivos de dos editoriales, dos bases de datos originales y el estudio interno y/o paratextual de varios textos, en particular, de Timimoun de Rachid Boudjedra.

\section{1. ¿Obras «oportunistas»?}

¿En qué medida la literatura producida por los escritores argelinos francófonos durante la guerra civil responde a una demanda francesa? Antes que una hipótesis de investigación, esta sospecha es, en principio, una reacción por parte de algunos escritores frente al prestigio asociado al solo hecho de publicar en el extranjero. El análisis estadístico seguido del análisis microtextual de la construcción de los destinatarios en una serie de novelas permite matizar el vínculo entre publicar en Francia y la existencia de una demanda francesa.

\section{1.a. El discurso de la «autenticidad» y el mercado}

No podríamos dar una definición precisa de «autenticidad». Palabra central durante los años setenta en Argelia con su equivalente árabe așāla, la «autenticidad», marcada por la ideología nacionalista, sería ante todo una relación de fidelidad para con el pueblo sostenida en un sistema de oposiciones entre lo Mismo y lo Otro que esencializa las identidades. Los europeos de Argelia utilizaron el mismo tipo de oposición cuando, para afirmar su estatuto como escritores, a pesar de su marginalización por París y de su arraigo como europeos en suelo africano, se oponían a los «escritores-viajeros»" (Audisio; Arnaud, 1964). Posteriormente los europeos de Argelia fueron remitidos, en bloque, a la «inautenticidad» por parte de los escritores argelinos musulmanes o de los críticos como Albert Memmi (1964) o Edward Said, a propósito de L'Étranger de Camus, y así 
hasta la actualidad. ${ }^{4}$ Este discurso de la «autenticidad» involucró una diversidad de antónimos definidos con mayor o menor precisión cuya importancia fue variando a lo largo de la historia.

Es sobre todo durante el período de la liberación que el tema de la «traición» nacional reaviva la acusación de «inautenticidad». Un periodista argelino hablaba en 1969 de «exotismo de bazar» a propósito de La Répudiation de Rachid Boudjedra calificando de «traición" política el hecho de criticar las costumbres argelinas antes que la explotación colonial al evocar «la complicidad lamentable que parece demandarle a un lector que sólo puede ser occidental» (B.M.S.:39). Durante los años setenta, un período dominado intelectualmente por el marxismo y por el psicoanálisis a la vez, aparece el tema de la «alienación» lingüística y psíquica. Se trataba de la legitimidad del uso del francés que, de acuerdo con el nacionalismo de tipo herderiano y con ciertas teorías lingüísticas tales como la hipótesis de Sapir y Whorf, se consideraba una contradicción expresarse en francés cuando la identidad del locutor era árabe. Viviendo con intensidad el «drama lingüístico» (Memmi), el «regalo envenenado» de la lengua francesa (Djebar), ciertos autores dejaron de publicar en francés por un tiempo (Malek Haddad, Assia Djebar, Kateb Yacine) mientras que otros encontraban una resolución a esta alienación en el erotismo y la violencia de la fecundación del francés por el árabe en un «amor bi-lingüe» (Khatibi). La ruptura con ese discurso de la «alienación» es, en buena medida, histórica y por lo tanto, generacional. Los escritores nacidos durante los años 50 hacen durante los años 80 un uso «desinhibido» del francés y promueven el «mestizaje». Se oponen así a los fundamentalistas en el poder que instrumentalizan la cuestión lingüística para marginar la corriente socialista. Como se advierte, la relación de los escritores con las lenguas no es inmutable y debe ser historizada.

El antónimo de la «autenticidad» se vuelve cada vez más un «oportunismo» mercantil que implica un sometimiento a la demanda "exótica» del público extranjero, es decir, reducir al otro a algunos clichés provenientes de la época colonial fácilmente consumibles. En su edición del 27 de mayo de 1997, el suplemento cultural El Watan titulado «Cultura exiliada o cultura del exilio» planteaba en esos términos la cuestión de la «autenticidad» de la literatura escrita en el extranjero: en su artículo «La identidad en espectáculo», el joven periodista Kamel Daoud consideraba que la cultura argelina en el exilio «acabó en la desnaturalización (...) simplificada y vulgarizada para el consumo del otro». Conscientes de estas críticas, la mayoría de los escritores argelinos publicados en Francia durante este período intentaron resguardarse. La noción de «testimonio» (Leperlier, 2016) les permitía dar cuenta de su presencia paradojal en Argelia y, por tanto, de un modo de «autenticidad» de su escritura. Sin embargo, el «testimonio» rápidamente devino estigma al mismo tiempo que la «literatura de urgencia» que operaba como su sinónimo. En 2002, Sofiane Hadjadj describe la «novela de urgencia» como «una respuesta a una demanda» francesa: se trataría de un producto "vendible" aun cuando contenga el mínimo sindical de temor y de violencia integrista, lo único capaz de suscitar la adhesión del público» (Benmalek). Conviene situar este dictamen: Sofiane Hadjadj publicó su primera colección de breves novelas en su joven editorial argelina Barzakh y, como todos los vanguardistas, se posicionaba con relación a sus prestigiosos competidores que publicaban en Francia homogeneizándolos de manera negativa.

La realidad de la publicación de los escritores argelinos en Francia es más compleja: su crecimiento espectacular (pasa de la mitad a los tres cuartos del conjunto de la producción argelina francófona entre 1995 y 2000, y registra unos sesenta títulos en 1998$)^{5}$ es, más bien, el resultado de una «oferta» que de una «demanda». En efecto, se podría hablar de una «demanda» de la 
edición francesa capaz de crear una «oferta» de literatura argelina, medible por ciertos casos de reconversiones profesionales hacia la literatura, en particular de parte de los periodistas que no podían ejercer su oficio. Es posible citar tres razones para esta «demanda». La primera es un interés creciente por las literaturas francófonas poscoloniales del sur (Ducournau). La segunda es una suerte de «soplo de aire fresco» provocado por el fallecimiento de tres de los escritores argelinos más importantes: Tahar Djaout, Rachid Mimouni y Rabah Belamri. Así, por 1996, la publicidad de la nueva revista parisina Algérie Littérature/Action, destinada a las comunidades, le prometía al público «descubrir la "nueva literatura argelina" que toma el relevo de una generación de escritores desaparecida prematuramente». La tercera razón obedece al interés francés por la cuestión política argelina. Jocelyne Cesary subraya que la guerra civil en Argelia se ha convertido en un verdadero «affaire francés», especialmente después de que el terrorismo se extendió a Francia a fines de 1994 (Cesary).

La situación argelina permite igualmente plantear las cuestiones de la laicidad y del islam en Francia, en particular en un contexto de refuerzo de las leyes de seguridad y de control de la inmigración establecidas por Charles Pasqua.

Pero más que una lógica de demanda, lo que se encuentra en el origen del incremento de las publicaciones en Francia es una lógica de oferta. En el contexto de la crisis económica y de seguridad que atraviesan la edición argelina, la publicación en Francia aparece como una solución alternativa cómoda, una extensión del dominio editorial argelino. Las curvas de la edición francófona en Argelia y en Francia son rigurosamente opuestas entre 1993 y 1997: este efecto de vasos comunicantes permite hablar de una «deslocalización» de la producción francófona. Así L’Harmattan, el más grande editor de escritores argelinos durante el período, en gran medida, financiado por los autores, pasa de un promedio del $7 \%$ de toda la producción en lengua francesa al comienzo de los años 1990 a un 18 \% entre 1992 y 1995 . Son especialmente las pequeñas editoriales las que aprovechan el crecimiento de la publicación de escritores argelinos cuya proporción pasa del 50 \% en la primera mitad de los años 1990 al 60 \% en la segunda mitad de la década. El aumento de la oferta encuentra así, inmediatamente, una demanda sumamente abierta (diversos pequeños editores o publicaciones por cuenta de los autores) y un mercado (lectorado) sumamente acotado. En definitiva, contrariamente a lo dicho por Sofiane Hadjadj, la literatura producida en Francia no podría reducirse a una «respuesta a una demanda».

\section{1.b. Textos Jano}

Si bien no es posible saber a qué lector, argelino o francés, apuntaba conscientemente el autor al escribir su texto, en contrapartida el análisis textual permite despejar su destinatario (que no necesariamente se corresponde con su lector real). Al seguir el curso típico de la transnacionalización de las obras, desde las más orientadas hacia un lectorado francés hasta las más orientadas hacia un lectorado argelino, se constata que la mayoría tiene, en realidad, un carácter bifaz: una especie de Jano que mira con mayor o menor intensidad hacia una o la otra orilla.

En primer lugar, es necesario subrayar que son pocos los textos, en particular novelas, de escritores argelinos que no supongan un destinatario argelino: salvo excepciones, el referente es generalmente argelino, en particular durante la guerra civil. Encontramos dos importantes excepciones a esta tendencia en dos escritores con un peso significativo en el espacio literario francés. La «Tétralogie nordique» de Mohammed Dib se publicó sobre el fin de los años 1980 sobre todo en 
Sindbad, pequeño editor de circuito más bien restringido. ${ }^{6}$ Por el contrario, Yasmina Khadra, con su «trilogía consagrada al diálogo de sordos entre Oriente y Occidente» ${ }^{7}$ formada por Les Hirondelles de Kaboul (2002), L'Attentat (2005) y Les Sirènes de Bagdad (2006) publicada por Julliard (editor integrado al grupo VUP, luego Editis) ha podido llegar a un público más importante: los dos primeros títulos vendieron más de centenas de miles de ejemplares y recibieron muchos premios. Estos casos de best-sellers argelinos que muestran una adecuación a los gustos del gran público francés (y más ampliamente, europeo) son extremadamente raros (Leperlier, 2017). Yasmina Khadra, que dio forma a su estilo con el policial lo logró manteniéndose lo más cerca posible de la actualidad violenta del mundo árabe-musulmán; su estatuto de argelino, supuestamente musulmán, le confirió una legitimidad mediática para expresarse sobre el tema. No obstante, esta adecuación al gran lectorado francés no implica desatender al lectorado argelino que rechazaría una escritura demasiado «exótica»: su éxito en Francia ha sido ampliamente repatriado en Argelia donde pasó a ser el autor más vendido en las ediciones locales.

Los recién llegados al espacio literario francés tienen, por lo general, muy en cuenta al destinatario argelino. En una entrevista, Salim Bachi nos decía, a propósito de su primera novela, Le Chien d'Ulysse, publicada por Gallimard en 2001: «Todo el mundo publica en París (...). Por eso yo me instalo en un paisaje literario parisino que, por más que se diga argelino es, sin embargo, parisino (...). Vengo con un libro que discute también esta literatura, ¿ves?» (2014). Esta afirmación puede interpretarse de dos maneras. Debido a su prestigio, la literatura argelina publicada en Francia, más precisamente en París, es autosuficiente y no necesita referirse a la publicada en Argelia. Pero también se entiende que, aunque publicada en Francia, esa literatura sigue siendo «argelina» (esto desde los años noventa: anteriormente era percibida como "magrebí»). De hecho, Le Chien d'Ulysse se inscribe prioritariamente en el campo literario argelino, rinde homenaje a Kateb Yacine y discute, en particular, lo que se ha presentado como «literatura de testimonio» que sería, a la vez, lineal, maniquea y comprometida. En general, de las aproximadamente cincuenta entrevistas que realizamos a escritores argelinos de la década negra, una sola novelista (la situación es diferente en poesía) citó espontáneamente a un escritor francés vivo contemporáneo, Pierre Michon, no para compararse con él sino porque él había hecho un comentario favorable sobre sus novelas.

De manera más inesperada, los textos publicados en Argelia frecuentemente tienen en cuenta además, un destinatario francés: es el caso de dos novelas publicadas en el momento de la fundación de ediciones Barzakh en 2000 cuando la probabilidad de circular en Francia era extremadamente baja. En Zarta de Mustapha Benfodil, los muy numerosos términos del árabe dialectal (y kabil) son sistemáticamente subrayados y traducidos en notas donde igualmente se hace referencia, con humor, al improbable caso de que «el libro salga en Francia debido a la interrupción de la libertad de expresión».8 En Maintenant ils peuvent venir de Arezki Mellal, el personaje de Lilia, beurette " "nacida en el "interior"» (14), en un relato que se sitúa al comienzo de 1990, permite al autor, desde el primer capítulo de la novela, dar convincentes explicaciones lexicológicas al vocabulario de los islamistas que se mantiene en árabe sin ninguna aclaración: «hoy entre los barbudos es layadjouz, es decir, ilícito para la religión» (15). La «cándida inmigrante» (15) pasa por el nuevo persa: «Lilia es de otro tiempo. El desfasaje es inmenso, ella era, sin embargo, mi semejante» (20). La mirada de la beurette permite mostrar la muy rápida evolución de Argelia. Sin embargo, el narrador, igualmente muy crítico respecto de su país y considerándose «extranjero» respecto de la hipocresía del ramadán, se niega a partir del modo en que ella se lo propone (20) y no comparte 
su mirada de extranjera que se vuelve explícita cuando la joven artista pinta la bahía de Argelia: «En mi Mediterráneo hay (...) esa luz que no pertenece más que a esas orillas. En el Mediterráneo de Lilia está la mirada de alguien que pasa, que va a pasar» (22). Mientras que Lilia quiere ver en la bahía de Argelia la típica «Casbah», el narrador, sucesor de los escritores de la Escuela de Argelia, ve el Mediterráneo que llega a «Nápoles, Atenas o Beirut» (21): el mundo y la esperanza a las puertas de la ciudad donde él quiere quedarse y no la imagen anticuada y exótica del turista. Con esta novela que es unánimemente presentada como una gran novela por los escritores con los que nos hemos reunido, Arezki Mellal, publicado en Argelia, procura plantear una mirada «auténtica» sobre la Argelia de la guerra civil. Sin embargo, tiene igualmente en cuenta a un destinatario francés que, de manera bastante cercana a la realidad sociológica del lectorado francés de escritores argelinos, es de origen magrebí.

\section{1.c. Decires y no decires del exotismo: Timimoun}

Los casos de reescritura de un texto entre Argelia y Francia son poco comunes. Sylvie Ducas ha mostrado la recuperación que Kamel Daoud hizo de su Meursault contre-enquête en las ediciones argelina (Barzakh, 2013) y francesa (Actes Sud, 2014). Probablemente de acuerdo con su editor francés y los derechohabientes de Camus, tanto el paratexto como el texto mismo se modificaron «orientando la recepción del libro en el sentido de un homenaje a Camus, y no un juicio» (Ducas:192-193) contra el que se presenta como el asesino del árabe. Ahora bien, como lo demuestra Kaoutar Harchi, es ante todo el homenaje a Camus lo que la recepción francesa retuvo de esta novela mientras que Daoud fue «conducido a adaptar estratégicamente su discurso promocional al horizonte de expectativas» francés (Harchi:208).

Otro caso límite, Timimoun, publicado en árabe en Argelia en 1994 (ENAG [al-Ijtihad]: Timimoun edición argelina [en adelante T-A]), luego en francés en Francia (Denoël: Timimoun edición francesa [en adelante T-F]) por Rachid Boudjedra, permite matizar la oposición entre dos destinatarios y la posibilidad misma de un decir «auténtico» en el caso de este nacionalista árabe, atento no obstante a esta apuesta (en particular luego de haber sido cuestionado por La Répudiation —ver más arriba-). Las temáticas políticas pueden dirigirse a dos públicos, aun si se inscriben de modo diferencial en la trama de los discursos sociales de los dos países. Lo que hemos llamado «la Andalucía feliz» (Leperlier, 2018b) muestra una imagen positiva de las relaciones entre las comunidades en la Argelia colonial: representada en el relato por Henri Cohen, el amigo judío y comunista del narrador, es extensible a los dos espacios en cuestión, el francés y el argelino. Mientras que en Argelia esta temática es sumamente subversiva en tanto pone en cuestión la gesta nacional marcada por lo religioso y sobre todo, por el antisemitismo de buena parte de la población, en Francia le permite al autor construir un ethos liberal y tolerante, tanto más necesario en el momento del combate radical contra los islamistas. Lo mismo ocurre con las temáticas subversivas para el Islam: el alcoholismo y la homosexualidad (subversivas aquí, y parte de un ethos liberal allá).

Más allá de estas temáticas políticas, se puede advertir que la novela interroga directamente el discurso social sobre Argelia al tematizar la mirada exótica sobre el país. Esta novela es la historia de las peregrinaciones reales y psíquicas de un guía turístico en el Sahara argelino, amante rechazado en el centro de los años 9o. Los turistas conducidos hacia el oasis de Timimoun perfilan al destinatario de este libro: «Quería, sobre todo, romper las ideas previas de mis clientes. Las ideas tarjetas postales o guías culturales con las que llegan, un poco ingenuamente» (T-F:60). El íncipit 
decepciona la expectativa del lector: «La noche cae densa». No se describe un lugar con sol sino durante la noche, incluso con lluvia, donde las reminiscencias de resplandores son las de los «flashes enceguecedores» de los vehículos cruzados por el ómnibus. «Ahora ya no hay más desierto. Queda el frío y subsiste un clima nocivo e inconsistente» (T-F:12). Las primeras páginas de la novela sumergen al lector en la intimidad sombría de un ómnibus ciego al afuera. Se trata de la imagen del narrador explorando sus sentimientos y su memoria en un monólogo interior: «Incluso de noche, [el desierto] es el lugar central de la angustia, del deseo y del vértigo» (T-F:16). El narrador se enamora de una mujer joven, Sarah, que como su nombre lo indica, se confunde con el Sahara: «La gente, alrededor de ella, nadaba en el magma mediocre de su deseo que consistía en no perderse nada del Sahara cuyos espejismos y leyendas los habían como dopado, drogado, enfermado./ Ella estaba realmente adentro. De lleno. En cada parada, en cada visita, se tornaba más transparente, magnética, exorbitante. Sus ojos cambiaban de color» (T-F:21).

Estas dos miradas sobre el desierto están en el fundamento de una estética de la antítesis: «El Sahara es desagradable. Es duro. Es insoportable. Sólo los turistas que están de paso lo encuentran idílico y cautivante». Pero la visión optimista de los turistas no es desestimada por completo: el narrador evoca el «desierto en su aridez y en su fecundidad; en su aspereza y en su suavidad» (T-F:38-39). Para este hombre «frígido» de 40 años, el deseo se mezcla con el miedo y con la muerte. Mientras describe con repugnancia un sexo de mujer, surge el recuerdo del anuncio de un asesinato: «esa carne tumefacta como destruida, mutilada a puñaladas... eso genera confusión... desorden.../ EL PROFESOR BEN SAID HA SIDO SALVAGEMENTE DEGOLLADO ESTA MAÑANA (...)» (T-F:31).

Se puede considerar que esta estética de la antítesis es constitutiva de lo que Graham Huggan (2001) denomina un «exotismo estratégico». Al cuestionar los clichés exóticos, el narrador los afianza pintando "gigantescas palmeras entrecruzadas a ambos lados» (T-F:88) de su ómnibus. La escena alrededor del desencallado del ómnibus es característica:

Había tomado esta duna, no para deslumbrar a Sarah sino para asustarla. Me llevó tres horas el desencallado. Ninguno de los pasajeros entró en pánico. Sarah tampoco. Ella me ayudó mucho a cavar la arena y a colocar, bajo las ruedas del ómnibus, todas las mantas de pelo de cabra y los albornoces de piel de camello. La mejor manera de quitar la arena si uno no quiere llevar palancas ni gatos hidráulicos demasiado grandes.

Las otras personas, subidas al techo del vehículo, contemplaron por largas horas esas montañas de arena leonada u ocre o roja o azafrán. Parecían encantadas, pero tres horas mirando el mismo aspecto del desierto es demasiado y muy peligroso. Le dije a Sarah: «Es así como uno se va volviendo loco, o mejor, místico». Ella sonrió, pero de una manera un tanto forzada».(T-F:72-73)

La ironía invade a los turistas, confinados al aburrimiento por la contemplación de los colores del lugar, mientras que el topos de la mística del desierto es degradada al rango de la insolación y de la locura. En el texto árabe, en lugar de las valoraciones de los colores contemplados por los turistas se encontraba nachwa al-khalā’ al-‘ārī (T-A:60), «el éxtasis del vacío desnudo»: cliché paisajístico aquí, cliché religioso allá, pero cliché en ambos casos. En cuanto al exotismo que el narrador cree compartir con Sarah, su gusto mórbido por el desierto (el «miedo», el sufrimiento), se atasca igualmente de manera ridícula. La actitud activa de Sarah se opone, ciertamente, a la de otros turistas. Pero la ayuda que le brinda al narrador es la oportunidad para valoraciones propiamente exóticas sobre la manera típica de desencallar un vehículo. En la versión árabe, estas se reducen a 
la evocación de la țarīqa taqlīdya (T-A:60), manera tradicional.

Es cierto que Boudjedra declara haber querido defraudar el horizonte de expectativa de su lectorado hablando del desierto "de una manera diferente, es decir, no exótica», ${ }^{10}$ pero resulta sorprendente, siguiendo esta estética de la antítesis, que un lector atento a la obra de Boudjedra como Patrick Grainville caiga en cierto exotismo cuando escribe: «Boudjedra nos descubre evocaciones impactantes del desierto, con sus dunas ocres y azafrán, sus cauces secos, sus lagos inmaculados» (Grainville).

Como señala Heba Ghadie, estos toques exóticos están menos marcados en la versión árabe del texto, debido a que el autor no puede jugar con las diferencias lingüísticas. Esto se observa en la descripción pictórica de un jinete tuareg: «Un mehari [méhari] se mueve en el desierto ocre y azafrán [safran], como inverosímil (...) Su jinete, una mancha azul, oscila lentamente. Atraviesa un lago de sal [chott] cegador de blancura» (T-F:61). Se traducen «mehari», «azafrán» y «chott» en lugar de «dromedario» y «amarillo» («chott», lago de sal, no tiene otra traducción en francés). Esto puede conectarse con la intención nacionalista de Rachid Boudjedra de afirmar la influencia árabe sobre el francés, apreciable en todas sus novelas. No obstante, llegado el momento de una descripción del desierto, esta preocupación política vira en exotización. A pesar de esto, no habría que exagerar la diferencia con la versión árabe (T-A:52): los dos textos actúan una misma estética de la antítesis a través de una distancia y de una presencia del cliché. La imaginería orientalista se advierte en la referencia pictórica, en el juego de los colores, pero lo borroso del dibujo (tartasim, se dibuja, mutabakhtirān, tenue) diluye el cliché en una alucinación de la que no queda más que un cuadro del estilo de los de Nicolas de Stäel. La lentitud del jinete, la base del desenfoque pictórico, se trabaja en francés a partir del juego de nasales y, en árabe, a través de las repeticiones y los paralelismos. La versión francesa presenta, sin duda, una descripción más subjetivizada remitiendo de modo más marcado a la mirada del espectador: el desierto es, así, «de una blancura enceguecedora» («aveuglant de blancheur») mientras que en la versión árabe es «blanco brillante» («blanc brillant»; nāṣii al-biyāộ). En este último caso se apela, además, a una frase hecha, a un cliché de la lengua.

Aunque la autotraducción le brindaba la posibilidad de una marcada reorientación del destinatario, Boudjedra se valió de sus libertades de manera marginal. Los turistas-destinatarios del texto no son particularmente franceses, sino indistintamente «autóctonos o extranjeros» (T-F:55): «a los turistas, extranjeros o no» (șẳihīn ajānibi kānū am lā, T-A:46). De hecho, los «autóctonos» del norte del país que constituyen la realidad de los turistas del Sahara son nutridos por los mismos clichés exóticos sobre el desierto que los «extranjeros». También de manera sorprendente, Boudjedra cita en la versión francesa al mariscal Lyautey que parece en sintonía con la visión no exótica del narrador: «Un continente frío donde el sol es caliente. Esta expresión es de un colonizador francés cualquiera, tan verdadera como conforme» (T-F:39).

$\mathrm{El}$ análisis de este texto permite poner fuertemente en cuestión los anatemas de oportunismo exótico lanzados contra los escritores francófonos de París: el exotismo está presente por una estética de la antítesis aun en aquel que lo denuncia, y la diferencia entre destinatarios franceses y argelinos, francófonos y de lengua árabe, es menos de naturaleza que de grado, lo que pone en cuestión la existencia misma de una lectura «auténtica». 


\section{2. ¿Una edición y una recepción «etnocéntricas»?}

El «etnocentrismo» en la recepción de las literaturas periféricas en un espacio central está ampliamente documentado y no se reduce al caso particular de las relaciones franco-argelinas (Jacquemond; Huggan; Harchi). Sin embargo, las conclusiones a las que se llega son a veces excesivas debido, probablemente, a una preocupación, en sí misma legítima, de denuncia política del tratamiento dado a los dominados en el espacio literario internacional." Como lo han mostrado los estudios de traducción, la importación descontextualizante (Bourdieu, 2002:3-8) de las literaturas periféricas se desarrolla en una fuerte coyuntura política (Sapiro; Popa): tal es el caso de la literatura argelina de la guerra civil. Pero la mayor diferencia reside en el hecho de que es posible hablar, en el caso de los escritores francófonos, de una «semi-importación» en la medida en que entran en el mercado francés sin pasar por la mediación de un traductor, lo que les permite un mayor margen de maniobra en la negociación con su editor y en el control de su recepción.

La recepción de Timimoun en Francia permite confirmar, matizándolos, los juicios que condenan la recepción francesa por su etnocentrismo. De igual forma, la edición francesa es diversa y no podría reducirse al etnocentrismo.

\section{2.a. Recepción política y literaria de Timimoun}

Desde los años 9o, la idea de un «etnocentrismo» de la recepción francesa, interesada en aspectos superficiales de la literatura argelina, circuló entre escritores, investigadores y periodistas. La investigadora Farida Boualit planteaba la cuestión de un "fenómeno de moda» y citaba a Hafsa Zinaï-Koudil afirmando: «La tragedia de mi país, retomada en todos los periódicos, se ha transformado en fondo de comercio lucrativo» (36)..$^{12}$ Charles Bonn lamentaba una espera, con frecuencia «más documental que literaria» (201), en la lectura de los textos literarios argelinos. Esta idea fue retomada por Aude Lancelin en el periódico Le Nouvel Observateur: Lancelin denunciaba un exotismo del horror «suscitando una lectura más documental que literaria en un público francés obnubilado por la cuestión política inmediata».

De hecho, la recepción francesa de Timimoun, muy importante si se la compara con la de otras obras de Boudjedra del período - unos sesenta artículos—, está ligada, en su mayor parte, a la actualidad política de Argelia. Con gran éxito, la novela sale rápidamente en formato de bolsillo y es seleccionada para el premio Goncourt y para el premio Populiste: el trabajo sobre los clichés exóticos está, por lo tanto, lejos de ser incompatible con un éxito francés. Además, la recepción política de este texto puede parecer sorprendente en tanto las cuestiones políticas ocupan en él un segundo plano y se reducen a la mención de algunos recortes de prensa sobre asesinatos y atentados en una tipografía diferente; sin embargo, es alrededor de estos que se concentran la mayoría de los artículos periodísticos. Es probable que Rachid Boudjedra haya buscado, con este texto escrito en «modo menor» y, tal vez, el menos politizado de todos, romper con su panfleto FIS de la haine publicado dos años antes. Este último constituye, a pesar de todo y muy claramente, el horizonte de expectativa de la prensa. Es que el novelista oscila entre dos compromisos: el literario y el político. El compromiso político es inescindible para él de su responsabilidad como intelectual y acrecienta la repercusión mediática de su texto, con el riesgo de restringir su recepción propiamente literaria. Así, luego de declarar su rechazo a ser comparado con un "politólogo» y un «periodista» (Nord-Eclair, 28 de mayo de 1994), confiesa más tarde que «Timimoun es un intento de sensibilización» de la opinión francesa frente a la situación argelina (L’Union, 17 de junio de 
1994) y no tiene reticencias en responder sobre cuestiones políticas. Por el contrario, multiplica su participación en debates públicos, en particular en los organizados por los órganos de prensa comunista. Es posible advertir, sin embargo, entre los artículos más politizados que citan su novela, un desplazamiento de su recepción hacia la derecha (hasta el momento, con frecuencia hostil a las violencias anti-colonialistas y anti-imperialistas de Boudjedra): diversos diarios de derecha toman a su novela como pretexto para referirse a la situación política argelina (Le Figaro, L'Express, France Soir, Ouest France). Este deslizamiento es el efecto de un malentendido político ligado a la transposición de problemáticas argelinas en Francia. En Argelia, la lucha contra los islamistas es, en realidad, un combate por la libertad — de credo, de la mujer, etc.—en un contexto donde el islam es la religión de Estado, donde la sociedad está fuertemente marcada por la religión y donde los radicales siembran el terror para imponer prácticas más rudas todavía. Ahora bien, en Francia no solo no hay religión de Estado y las costumbres son considerablemente más liberales, sino que además el islam es una religión minoritaria y los musulmanes, una población socialmente minoritaria: se comprende, por lo tanto, que en el contexto de las pujas de seguridad e identitarias con una fijación sobre el islam en Francia, la recepción de Boudjedra se deslice a la derecha.

Sin embargo, sería inexacto reducir la recepción francesa de Timimoun a una recepción política. Algunos artículos intentan encontrar un equilibrio entre las cuestiones políticas y la atención a las temáticas y al estilo del texto dejando de lado incluso la cuestión política. Esto se advierte en la prensa especializada en la «región» (mundo árabe o África): Qantara, Hommes et migrations, Jeune Afrique, Maghreb Magazine. Es posible explicarlo por una tendencia, menos expandida entre los periodistas familiarizados u originarios de África del Norte, a reducir esta literatura exclusivamente a su dimensión política. Se puede, igualmente, enunciar la hipótesis de que esos periódicos especializados tienen más oportunidades de referirse a la situación política en Argelia, al margen de sus crónicas culturales. Podría ser legítimo, entonces, calificar de «etnocéntricos» a los periodistas no especializados de la «región», cuando se valen de la novela como pretexto para referirse a lo que es susceptible de interesar a su público: la actualidad política del terrorismo islamista. Pero también se puede explicar esta diferencia de tratamiento de otra manera. Nos parece que el elemento central de la explicación es la periodicidad reducida de esta prensa especializada en la «región» (se trata de publicaciones mensuales, en ocasiones semanales) que les permite a los periodistas distinguirse por un enfoque menos subordinado a la actualidad: comparte esta característica con la prensa especializada en literatura (Le Magazine littéraire, Le Figaro littéraire) donde también se encuentran artículos desligados de la política. A menudo los autores de estos artículos no son solamente periodistas sino también escritores (Patrick Grainville, Le Figaro littéraire; Arezki Metref, Politis; Jean-Claude Perrier, Afrique Magazine) o universitarios (Charles Bonn, Hommes et Migrations).

Cabe señalar, por el contrario, que en El Watan, periódico argelino de lengua francesa que le dedica el mayor espacio a la literatura, los tres artículos que aparecen en junio y julio sobre Timimoun dedican una parte importante (11 de julio), e incluso central (15 junio), a la cuestión política. Solo en la edición del 18 de octubre de 1994, en un dossier consagrado a Boudjedra por haber sido seleccionado para el Goncourt, se publican artículos sobre todo literarios, junto a artículos claramente políticos. Solo de forma demasiado apresurada se podría concluir que la lectura francesa es únicamente «documental» $\mathrm{y}$ «etnocéntrica», y que reduce el sentido de las obras a sus aspectos más mediáticos y, por lo tanto, políticos; una recepción que se opondría solapadamente a una lectura argelina más diversa, más «auténtica». El criterio que distingue lecturas políticas de literarias 
sería, más bien, la periodicidad de esas publicaciones. Las recepciones propiamente literarias de Boudjedra se perpetúan en Francia en el momento de su mayor éxito mediático en el corazón de la guerra civil. Y preceden a las que luego tendrán lugar en Argelia.

\section{2.b. Un espacio editorial francés polarizado}

La misma sospecha de etnocentrismo cae sobre la edición francesa, con un recelo aún más fuerte dado que esta sería susceptible de modificar al contenido del texto para ajustarlo a las expectativas del público al que se dirige. El prologuista francés de L'Insurrection des sauterelles de Hassan Bouabdellah habla incluso de una «máquina editorial que tritura a los autores» (Zimmermann:6): aquí, otra vez, es la preservación de una «autenticidad» argelina lo que está en juego, como lo sugiere el prologuista a propósito de este texto que «se inscribe en la perspectiva mental argelina» y trabaja el francés «del interior» con el «genio argelino», «sin complacencia» respecto del público francés.

No se trata de objetar en bloque esta afirmación, sino de demostrarla más que de invocarla, y de matizarla. De hecho, la edición francesa no es monolítica, como lo ha mostrado Pierre Bourdieu: podemos oponer, al menos, un polo de gran producción que se fija objetivos de rentabilidad a corto plazo y aparece por esta razón muy vinculado con la actualidad mediática, y un polo de producción restringida, más preocupado por la acumulación de capitales simbólicos a largo plazo. En los años 1990, la edición francesa inicia, es cierto, una «revolución conservadora» (Bourdieu 1999) que refuerza su polo de gran producción.

En este polo, ciertos casos extremos muestran un rol muy activo del editor francés en la «fabricación» de la literatura argelina. Es el caso de Vivre traquée de Malika Boussouf, publicada en Calmann-Lévy en 1995. Nacida en 1954, esta periodista francófona, amenazada de muerte por sus tomas de posición radicalmente anti-islamistas, es introducida por una editora de Calmann-Lévy luego de una manifestación de apoyo a los intelectuales argelinos. Ella acepta escribir un libro para ampliar su trabajo como periodista política que, durante una entrevista, rotula como «ensayo» (Boussouf). No obstante, el estatuto genérico del texto es objeto de una negociación con su editora, quien le pide, en un segundo momento, que agregue más elementos autobiográficos:

\footnotetext{
—Bueno, digamos que... que me exigieron esos flashbacks. Eso.

—¿Quién? ¿Con qué objetivo?

—El editor, y bueno, creo que porque vende más. (Boussouf)
}

Dedicada sinceramente a la escritura de este testimonio, la autora interiorizó a su vez los condicionamientos económicos del editor. Los «umbrales» del libro revelan una negociación similar. Mientras que en el prefacio la autora explica haber elegido una "palabra oblicua» a través de la utilización de la tercera persona, la contraportada suprime toda ambigüedad: «Vivre traquée es su historia». Y precisa, mientras que ninguna indicación genérica aparece en la primera página: «Rechazando la grandilocuencia, este testimonio conmovedor de una mujer en libertad condicional que desafía la barbarie y denuncia a sus cómplices es también el reportaje más mordaz sobre un país al borde del abismo». En cuanto a la portada, presenta la foto de una escalera de la alcazaba de Argelia, por la que sube una mujer ligeramente encorvada con su haik y una niña que mira al fotógrafo. De este modo, el editor presenta un conjunto de elementos susceptibles, en su opinión, de interesar al lector: informaciones de actualidad documentadas «sin concesión» («el reportaje más 
mordaz»); narración directa (sin «grandilocuencia») y patética («conmovedor») pero igualmente dramatizada («en libertad condicional», «al borde del abismo») y heroica de la lucha maniquea del débil («mujer») que obtiene la victoria («desafía a la barbarie»); exotismo de origen colonial (la mujer en haik en la alcazaba no es «típica» del fundamentalismo de los años 1990 pero recuerda a las representaciones coloniales) y violencias ligadas al islam («barbarie»). ${ }^{13} \mathrm{Si}$ bien está de más decir que las capacidades de negociación de una recién llegada al campo literario son escasas, Malika Boussouf no parece lamentar el resultado de esta negociación. Cabe destacar, en efecto, que la negociación puede transformarse en conflicto, como lo muestra Isabelle Charpentier (144) a propósito de la escritora Leïla Marouane y la editorial Julliard. Estos conflictos son, en parte, el resultado de la circulación transnacional de esta literatura, como lo señala Christine Détrez: «la escritura de sí y el testimonio, transgresores en el sistema cultural tradicional tanto como la denuncia de las desigualdades que moldean la condición femenina, se convierten en estereotipos en el sistema editorial francés contribuyendo a deslegitimar tanto el alcance literario como el subversivo» (224).

Pero no toda la edición francesa se reduce a este polo de gran producción. En el polo de producción restringido, en Francia, ciertos editores han sabido llevar adelante un trabajo de descubridores de escritores argelinos o han publicado textos considerados difíciles, lo cual no era frecuente en Argelia debido a las condiciones políticas y económicas menos favorables. Pensamos en Seuil durante los años 9o, en Sindbad durante los años 70-80 (editor francés paradojalmente financiado por Argelia - Santini-), en pequeños editores de poesía o de teatro (La Rougerie, Lansman en Bélgica) e incluso, en los años 9o, en la revista Algérie Littérature/Action. Esta última se proponía abrir para la literatura «un lugar autónomo, alejado de las presiones económicas e ideológicas» (alude a la situación argelina —ideológica— pero también a la francesa —económica一) que logra constituir gracias al militantismo benévolo de sus colaboradores y a las subvenciones públicas francesas (Leperlier, 2015). Ahora bien, son especialmente los pequeños editores los que se hacen cargo de los escritores argelinos durante los años 90.

Durante este período, el caso de Seuil está en medio de estos dos polos: busca preservar su categoría de editorial literaria exigente evitando correr demasiados riesgos. En contraposición al voluntarismo político de la editorial durante los años 50 y con la colección Méditerranée dirigida por el escritor pied-noir Emmanuel Roblès (Serry), no se publica durante los años 90 ningún autor nuevo que no haya sido reconocido por otro editor. En 1996, el editor Louis Gardel confesaba que Le Seuil formaba parte de los «editores instalados, a veces tibios» que no pueden permitirse publicarlo todo y se alegraba por la aparición de la revista Algérie Littérature/Action como un «laboratorio» que les permitía a los editores «detectar autores» (1996:212). La nota de lectura hallada en el archivo de Seuil sobre la novela Camping de Abdelkader Djemaï en 2002, publicada hasta entonces por Michalon, permite comprender las lógicas operantes:

\section{Nota de lectura de Camping ${ }^{14}$}

Contenido del libro. (...) A través del microcosmos de este Camping se evoca la Argelia anterior a la catástrofe, como el film de Tati era una evocación de la Francia de posguerra.

En resumen: Abdelkader Djemaï escribe en una lengua aparentemente muy simple pero, en realidad, muy trabajada. Es un verdadero escritor (el manuscrito se ha etiquetado Grainville et Visage) y es desde esta perspectiva que conviene promoverlo. Camping no es un libro político ni ideológico ni polémico. Es más profundo. 
Argumentos comerciales: Tiene una buena imagen en la prensa, conoce a muchos escritores y goza de una gran estima. Hay un lugar para él en Seuil, en la línea de autores magrebíes que se volvieron una especie de clásicos.

La preocupación por la «universalidad» de la literatura de la que habla Louis Gardel en nuestra entrevista, cuando este nativo de Argelia dice rehusarse a constituir "guetos» argelinos, muestra el intento de presentar a Djemaï como un "verdadero escritor» sin etiquetado nacional: en la contraportada no aparecerá, por otra parte, el nombre de Argelia. Este problema de la universalidad pasa por el rechazo a publicar literatura política, en ruptura con la tradición de los años 50. En la nota de lectura las publicaciones de entonces son presentadas en términos de "clásicos» puramente literarios: «Le Seuil ha publicado a muchos autores, en especial argelinos, por otro lado, y lo hizo, al comienzo, por razones tanto literarias — porque no publicábamos cualquier cosa — como ideológicas» (Gardel, 2005). Cabe señalar, no obstante, que este rechazo de lo político no estaba tan claro en los años 9o. Los archivos de la revista AlgérieLittérature/Action muestran que las consideraciones políticas no fueron excluidas por Louis Gardel en la sesión de derechos de Peurs et mensonges de Aïssa Khelladi cuya contraportada en Seuil hace referencia a Argelia y describe el texto como «más allá del testimonio». Y, de hecho, siguiendo la distinción operada por ediciones Minuit entre literatura y política durante la guerra de Argelia (Simonin), mientras que esta novela se publicó en la colección «carré rouge», el testimonio recogido y rescrito por la periodista Baya Gacemi, Moi, Nadia, femme d'un émir du GIA, que obtuvo gran éxito en Argelia, ${ }^{15}$ se publicó en la colección Ciencias humanas y Documentos. Como se observa, las lógicas literarias, políticas o comerciales pueden variar dentro de una misma editorial. Lejos de reducir sistemáticamente la literatura de los escritores argelinos a documentos políticos ficcionalizados y comercialmente rentables, los editores franceses tienen actitudes diferentes frente a la «revolución conservadora» que los afecta, según su posición, entre los polos de gran producción y de producción restringida.

\section{Conclusión}

Los escritores argelinos publicados en Francia no están, sin duda, «alienados», en el sentido de ser extranjeros a sí mismos. Más que una realidad, la «autenticidad» y sus antónimos son, ante todo, anatemas lanzados por aquellos indignados por el reconocimiento otorgado a quienes tuvieron la oportunidad de publicar en el extranjero. Nuestro análisis puso seriamente en cuestión, por si fuera necesario hacerlo, la idea de la existencia misma de una escritura «auténticamente» argelina. Por el contrario, un destinatario francés, aún improbable, es tomado en cuenta con frecuencia por los escritores argelinos que publican en Argelia y, probablemente, por todos los escritores francófonos no franceses (incluso por todos los escritores periféricos, en relación con los centros literarios internacionales). Pero, en la misma medida, se tiene también en cuenta a un destinatario argelino. Publicar en Francia no significa, necesariamente, tener en cuenta a un lectorado francés, en la medida en que Francia es, en primer lugar, una extensión del dominio editorial argelino. La diferencia entre la consideración de los lectorados debe pensarse como una diferencia de grado. El caso de Timimoun muestra que poner en cuestión los clichés «exóticos» es, incluso, una manera de renovarlos, y que las diferencias entre los destinatarios y los lectorados francófonos y de lengua árabe, extranjeros y argelinos, son mínimas (aun si no hay que desconocerlas). En cuanto al «etnocentrismo» de la edición y de la recepción francesas, es muy real. Pero, por un lado, se trata de un dato 
constante de las relaciones de fuerza entre centros y periferias literarias; tampoco es posible, por el otro, reducirlo solo a esto. Se pueden diferenciar un polo de edición y de recepción particularmente sometidos a la rentabilidad a corto plazo que privilegian los aspectos más «exóticos», «documentales», políticos de la literatura argelina. Pero no podríamos pasar por alto, asimismo, un polo (en parte subvencionado) que trata de sustraerse a ello y está tan atento, si no más que en Argelia, a la originalidad literaria de los textos propuestos. Además, contra el discurso de victimización del escritor, es necesario subrayar que este no tiene una actitud pasiva frente al aparato de edición y de recepción francés sino que es capaz, según su antigüedad en el campo, de negociar con su editor y de intentar controlar su recepción en función de fines literarios, comerciales y/o políticos.

\section{Notas}

1 Agradecemos al equipo de Littérature la autorización para traducir «D’Alger à Paris: des écrivains «aliénés»?» de Tristan Lepelier, y luego, para ponerlo en circulación. Este artículo apareció en el número 189 de la revista, publicado en marzo de 2018 (30-48). [Nota de los traductores]

2 Se podría agregar un espacio literario multilingüe (cf. Leperlier, 2019).

3 Sobre la censura en Argelia, ver Gafaïti (68-69).

4 «Los escritores argelinos de origen europeo habían fracasado en aproximarse lo más posible a la auténtica Argelia» (Sayeh:32).

5 Según nuestra base de datos bibliográficos original de alrededor de 1800 títulos de literatura publicados por escritores argelinos entre 1988 y 2003.

6 Títulos publicados en Sindbad: Les Terrasses d’Orsol (1985), Le Sommeil d’Ève (1989), Neiges de marbre (1990). Títulos publicados en Albin Michel: L’Infante maure (1994).

7 http://a-plume-francophone.over-blog.com/article-5120747.html

8 Tercera parte, tercer capítulo, nota 135 (documento sumi9 Término utilizado para hacer referencia a una joven nacida en Francia, hija de padres magrebíes [Nota de los traductores].

10 Comentario recogido en Afrique-Magazine, en junio de 1994. 11 De este modo, en su último estudio, Kaoutar Harchi se expide, de manera muy general y a partir de análisis mucho más matizados, sobre la "propensión etnocéntrica del aparato crítico francés» y considera que «colocados en el centro de luchas en las que el texto no es más que pretexto para los escritores, son instrumentalizados» (Harchi:255, 289).

12 La cita exacta es «La tragedia, siempre vuelta a empezar de mi país, retomada en todos los periódicos, se ha transformado en un fondo para el comercio lucrativo». Sans voix. Paris: Plon, $1997,128$.

13 Los términos entre comillas están tomados de la contraportada.

14 IMEC, Archivos de Seuil, SEL 4599.2, carpeta DB DJ. 15 http://www.vitaminedz.com/biographie-baya-gacemi/Articles _20916_2879817_23_1.html, consulté le 25 juillet 2015.

\section{Referencias bibliográficas}

Angenot, M. (1989). 1889: Un état du discours social. Longueuil: Le Préambule.

Archives Algérie Littérature/Action, 20 juin 1996

Audisio, G. (1943) L'Algérie littéraire. En Encyclopédie coloniale et maritime. Paris: Ediciones Jeanne Laffitte, 12.

B.M.S. (1969). La Répudiation de Rachid Boudjedra. L’Afrique littéraire et artistique 8 (diciembre), 39.

Bachi, S. (2014). Entrevista por Tristan Leperlier. Paris, 26 de mayo.

Benmalek, S. (2002). La seconde vie du roman algérien. Le Matin, 29 de agosto.

Bonn, Ch. (1997). Le retour au référent. Algérie Littérature/Action, (7-8), 201. 
Boualit, F. (1999). La littérature algérienne des années 90: Témoigner d'une tragédie? En Bonn, Ch. y Boualit, F. Paysages littéraires algériens des années 90 : témoigner d’une tragédie? Paris/Montréal: L'Harmattan.

Bourdieu, P. (1999). Une révolution conservatrice dans l'édition. Actes de la recherche en sciences sociales, (126-127), 3-28.

(2002). Les conditions sociales de la circulation internationale des idées. Actes de la recherche en sciences sociales, (145), 3-8.

Boussouf, M. (2014). Entrevista por Tristan Leperlier. Argelia, 20 de abril.

Casanova, P. (2008). La République mondiale des lettres. Paris: Le Seuil.

Cesary, J. (1994-1995). L'effet «Airbus». Les Cahiers de l'orient, (36/37), 175-191.

Charpentier, I. (2013). Le Rouge aux joues : virginité, interdits sexuels et rapports de genre au Maghreb. SaintÉtienne: Publications de l'Université de Saint-Étienne.

Détrez, C. (2012). Femmes du Maghreb, une écriture à soi. Paris: La Dispute.

Ducas, S. (2015). L'entrée en littérature française de Kamel Daoud: Camus sinon rien! Littératures, 73(2), 185-197.

Ducournau, C. (2017). La Fabrique des classiques africains: Ecrivains d'Afrique subsaharienne francophone, 1960-2012. Paris: CNRS éditions.

Gafaïti, H. (1997). Between God and the President: Literature and Censorship in North Africa. Diacritics, (27), 59-84.

Gardel, L. (1996). Algérie Littérature/Action, (5), 212.

(2005). Entrevista por Tristan Leperlier. Paris, 6 de mayo.

Ghadie, H. (2008). Rachid Boudjedra autotraducteur. Ottawa: Université d'Ottawa.

Grainville, P. (1994). L'Haleine de la mort. Le Figaro Littéraire, 20 de mayo.

Harchi, K. (2016). Je n'ai qu'une langue, ce n'est pas la mienne: des écrivains à l'épreuve. Paris: Pauvert.

Huggan, G. (2001). The Postcolonial Exotic: Marketing the Margins. London/New York: Routledge.

Jacquemond, R. (2003). Entre scribes et écrivains : le champ littéraire dans l'Egypte contemporaine. Paris/Arles: Actes Sud.

Lancelin, A. (1999). Rentrée littéraire. La renaissance du roman algérien: les enfants de l'amertume. Le Nouvel Observateur, 2 septembre.

Leperlier, T. (2015). La revue Algérie Littérature/Action. Fragilité d'un capital transnational entre l’Algérie et la France pendant la «décennie noire». Paris: CESSP.

- (2016). Témoins algériens de la «décennie noire» en France. Sociologie d'une dé/valorisation transnationale. Europe, (1041/1042), 178-191.

(2017). Littérature algérienne : le best-seller introuvable ? Revue critique de fixxion française contemporaine, (15), 175-188.

(2018a). Algérie, les écrivains dans la décennie noire. Paris: CNRS Éditions.

(2018b). L'Algérie coloniale, ou l'Andalousie heureuse. Socio-anthropologie, (37).

(2019). On Islands and Deserts: Algerian Worlds. Journal of World Literature, 4(1), 215-235.

Memmi, A. y Arnaud, J. (Eds.) (1964). Anthologie des littératures maghrébines. Paris: Présence africaine.

Miliani, H. (2002). Une Littérature en sursis?: le champ littéraire de langue française en Algérie. Paris: L'Harmattan.

Popa, I. (2010). Traduire sous contraintes: littérature et communisme, 1947-1989. Paris: CNRS Éditions.

Said, E. (2000). Culture et Impérialisme. Paris: Fayard/Le Monde diplomatique. Traducido al francés por Paul Chemla. 
Santini, M. (2006). Paris, librairie arabe. Marseille: MSH.

Sapiro, G. (2002). L'importation de la littérature hébraïque en France. Actes de la recherche en sciences sociales, (144), 80-98.

Sayeh, S. (2010). La Génération de 52: Conflits d’hégémonie et de dépendance. Paris: Publisud.

Serry, H. (2008). Les Editions du Seuil: 70 ans d'histoires. Paris: Le Seuil.

Simonin, A. (1996). La littérature saisie par l'histoire [Nouveau Roman et guerre d'Algérie aux Éditions de Minuit]. Actes de la recherche en sciences sociales, (111), 59-75.

Zimmermann, B. (1998). Algérie Littérature/Action, (18/19), 6-10. 